\title{
Analysis of the Online and Offline Hybrid Teaching of Traditional Chinese Medicine Classics
}

\author{
Zhaowen Li' ${ }^{1}$, Yingying Tan ${ }^{2 *}$ \\ ${ }^{1}$ Graduate College, Shaanxi University of Chinese Medicine, Xianyang 712046, Shaanxi Province, China \\ ${ }^{2}$ Typhoid Golden Deficient Teaching and Research Office, Shaanxi University of Chinese Medicine, Xianyang 712046, \\ Shaanxi Province, China \\ *Corresponding author: Yingying Tan, tanyy@sntcm.edu.cn \\ Copyright: () 2022 Author(s). This is an open-access article distributed under the terms of the Creative Commons Attribution License (CC \\ BY 4.0), permitting distribution and reproduction in any medium, provided the original work is cited.

\begin{abstract}
Distance education had sufficient technical capabilities before the novel coronavirus outbreak, but its advantages were not reflected in the normalized school running model. In the early stage of the pandemic, many students were affected and could not return to school. Many schools implemented online teaching to avoid delaying classes. After the alleviation of the pandemic, several colleges and universities taught students with a combination of online and offline methods after returning to school. The integration of online and offline teaching is conducive to the overall improvement of teaching quality in colleges and universities. This paper summarizes the shortcomings of the existing online and offline integrated education model in the teaching of traditional Chinese medicine classics in hope to further optimize the modern education system of traditional Chinese medicine courses.
\end{abstract}

Keywords: Teaching mode; Classics of TCM; Autonomous learning; Cooperative learning

Online publication: January 24, 2022

\section{Introduction}

As two different teaching methods, online teaching and offline teaching need to undergo two processes: mechanical integration and organic integration. At present, online teaching and offline teaching are in a stage of mechanical integration ${ }^{[1]}$. In the future, it is hoped that online and offline teaching can achieve full organic integration and help students adapt better to their university life under the pandemic. In February 2020, the Guidelines on Organizing and Managing Online Teaching in Institutions of Higher Learning during the Epidemic Prevention and Control of the Ministry of Education Leading Group Office on Novel Coronavirus Infection Pneumonia put forward the necessity to ensure that the quality of online learning and offline classroom teaching is essentially equivalent ${ }^{[2]}$. Based on traditional Chinese medicine courses and practical experience, this paper discusses the online-offline hybrid teaching implemented during the pandemic, in order to initiate discussions for improvement.

\section{Online and offline hybrid teaching is conducive to improving teaching quality}

Electronic informatization does not only bring convenience to people's lives, but also greatly improve people's work efficiency. Under this background, the traditional education mode can no longer fully meet the needs of students. Various online education platforms and software have sprung up to occupy the education market, especially during the pandemic period when traditional teaching cannot be carried out as 
usual. Online and offline hybrid teaching has become the mainstream teaching means in China. In recent years, the field of e-commerce in China has developed rapidly; the success of e-commerce can be used by the educational community. It is inevitable to comply with the trend of the times and use the advantages of openness, sharing, service, flexibility, and informatization in the field of e-commerce for education ${ }^{[3]}$.

In China, during the pandemic, 1,454 colleges and universities carried out online teaching, 1.03 million teachers offered 1.07 million courses online, and 17.75 million college students participated in online learning.

\subsection{Pre-class preview to determine learning objectives}

In the past, offline teaching was often classroom-centered, and pre-class and post-class learning were left to students to complete independently. Preview is generally for students to read before class. In this way, the effect of preview varies from person to person. Students with solid basic knowledge and rich extracurricular reading often understand the course; hence, the preview effect is good. However, for students with weak basic knowledge, preview is difficult, so many of these students do not have an option but to neglect the preview step, thus widening the gap with the former group of students. The most distressing point is that no matter how the students preview, it cannot be used as reference information for teaching. Before the outbreak, many teachers and students had recognized this problem, but the idea was left unattended because of the lack of appropriate platform technical support. However, now, teachers can provide help to students in the pre-class preview stage.

As the original text of TCM classics is far from today, there are many famous experts who had interpreted the original text and plainly, there are disputes over some interpretations. The preview of TCM classics allows students to go through some reading materials by quoting classics, quoting from others, and making oblique references. This can effectively spark students' curiosity, help them to build a knowledge system, add to their interest for the following courses, truly realize Rousseau's discovery learning, and is of great benefit to the cultivation of traditional Chinese medicine thinking. For some key and difficult points, teachers can use the platform to set reading cards or topics to follow-up with students' preview. In class, they can make full use of the feedback information to coordinate their teaching and summarize the problems encountered during the preview.

\subsection{Key points of classroom learning}

At present, the online platform courses only include videos recorded by teachers in advance, which cannot be separated from the traditional teaching mode. As teachers are still the main body in class, students only have the right to passively accept and act as audiences. For this reason, compared with the traditional mode of school teaching, this seemingly novel online teaching is in fact just "new wine in old wineskin," which is not a breakthrough innovation. Even the teaching effect may not be as good as school teaching. At school, teachers can discipline students who do not meet the code of conduct face-to-face. However, in online education, no one cares whether the students are sleepy or distracted. The online and offline hybrid education mode can be used instead as flipped classroom has more advantages ${ }^{[4]}$. Task-oriented learning involves teachers putting forward problems in consideration of the feedback from the pre-class preview and dividing the students in groups for discussion. In this process, both teachers and students are completely in mutual companionship and progress, thus truly achieving the common pursuit of teachers and students.

\subsection{After-class review determines the effect of learning}

In traditional offline teaching, the teaching process is disposable, and it is difficult to make up for the knowledge points missed by students in classroom. Unless they consult the teacher, their classmates, or 
relevant literatures, some introverted students tend to give up learning the knowledge point. There is no such issue with online and offline hybrid education. In addition to learning in class at specified teaching time, students can watch videos after class for new knowledge consolidation and learning. For some difficult topics, they can watch and learn again until they understand them. Even if they still have doubts, they do not have to go to the teacher's office and ask the teacher face-to-face. Online education platforms such as DingTalk and WeChat offer students a direct establishment of private channels with the teacher, saving a lot of trouble and embarrassment.

Moreover, teachers can also further plan students' review after class by using the auxiliary function of the online platform. The learning of classic ancient prose focuses on understanding and memorizing. Online education platforms generally prepare for after-school application and check what students have learned in class anytime and anywhere by filling in the blanks, multiple choice, etc. There are also some platforms that allow teachers and students to speak freely, discuss various difficulties faced in life and learning, as well as help teachers and students progress. Teachers, as elders, can convey warm feelings by giving positive responses to students. Online education may contain more humane interest than offline education.

\section{Suggestions for the new model of education}

As of now, the online and offline hybrid education is still a new teaching mode, which is in the experimental stage. Therefore, there are still many deficiencies that require improvement.

\subsection{Helping students develop and follow more appropriate learning plans}

Modern technology allows daily planning according to the situation of each student. If students learn at home, it is inevitable that the time for studying and resting will be irregular. However, they can be interspersed with reminders having considered their sleeping patterns, personal hobbies, and curriculum arrangements, so as to have a positive impact on the improvement of students' personal health and learning efficiency. It can also be used to calculate the Ebbinghaus curve at the end of the course to remind students of an appropriate time for review. Such artificial intelligence (AI) programs can help students with their work and maintain a relatively regular life even at home.

\subsection{Joining intelligent facilities to live and learn healthily}

In the curriculum arrangement of ordinary universities, physical education is only arranged for junior courses. It is known that college students face the problem of insufficient physical exercise. During the pandemic period, the learning environment of most college and university students is based at home, and some communities had taken restrictive measures such as staying at home unless required to go out; in addition, the lack of sports facilities in the community also adds to this issue. Somatosensory intelligent games can be integrated into the teaching application to encourage students to participate in sports. In addition, due to the lack of face-to-face supervision by teachers, some students with weak self-control may not listen during class; instead, they engage in irrelevant activities while the course is ongoing. Integrating some somatosensory systems may help to strengthen student management.

\subsection{Emphasizing on the humanistic care of teachers}

The purpose of online education is to make up for the shortcomings of offline education. Education is people-oriented, and human educational activities originate from communication. In a certain sense, education is a unique human communication activity ${ }^{[5]}$. Carrying out online and offline hybrid teaching can free teachers from repeated teaching tasks and improve their teaching efficiency, but this does not mean that the requirements for teachers are less. On the contrary, it means that the requirements for teachers are 
higher. Online education has changed the traditional relationship between supply and demand of teachers and students. A truly excellent teacher should not only teach what is found in textbooks, but also devote patience, love, sense of responsibility, and humanistic feelings to teaching. A good teacher should not only be a guide on the professional road of students, but also light the fog on the road of students' growth.

In this case, the mode of online teaching with mixed class and offline teaching with small class can be adopted, and class meetings can also be held regularly. Unlike the standardized and fixed procedure, people have emotions, and these emotions can be conveyed to another person. Their anxiety in the face of strange knowledge needs to be comforted by the calm tone of the elderly because positive memories are certainly more conducive to mastering knowledge.

\subsection{Improving the pre-class preview}

Many university teachers do not make full use of the advantages of online teaching platforms to guide students' preview. They still use the traditional preview method and do not take effective guidance on students' preview method. In fact, many college students still do not know how to preview scientifically and operate specifically. In regard to this, colleges and universities should uniformly provide teachers with training related to the "task guided" and "flipped classroom" learning models.

\section{Conclusion}

In his 1918 publication of Peking University Monthly, Yuanpei Cai explained that a university is an institution that includes the great classics and gathers all schools. The Book of Rites and the Doctrine of the Mean mentioned that "all things can grow together without harming each other, and the codes of conduct can be implemented without contradiction." It is like the human body; there is a left and right side, air comes in and goes out, and there is hardness and softness alike flesh and bones. Things that seem to work against one another often work for the other, such as idealism in philosophy, idealism and realism in literature and art, interference and laissez faire in accounting, motivation and utilitarianism in ethics, as well as optimism and pessimism in cosmology. This is the general principle of freedom of thought, and this is what makes a university great ${ }^{[6]}$. After the pandemic, online and offline hybrid teaching should be continued. With rich teaching resources on online platforms, students can achieve self-learning and understanding. The offline discussion between teachers and students can comprehensively and objectively reflect students' mastery of knowledge, promote peer pressure, stimulate students' enthusiasm, as well as assisting their learning and growth in the field of traditional Chinese medicine.

\section{Funding}

National Natural Science Foundation of China (Number: 81873296) - Effect Mechanism of Gualou Xiebai Banxia Soup on P2X7R /NLRP3 Improvement of Sympathetic Nerve Remodeling in Myocardium Based on the Theory of "Being Faint in Yang and String in Yin."

\section{Disclosure statement}

The author declares that there is no conflict of interest.

\section{References}

[1] Xue C, Li J, 2021, Interaction and Boundary between Online and Offline Teaching. Journal of Teaching and Management (Primary School Edition), 2021(9): 1-4. 
[2] Ministry of Education, 2020, Guidelines of the Leading Group Office for Novel Coronavirus Infection of the Ministry of Education on Organizing and Managing Online Teaching in Institutions of Higher Learning during the Epidemic Prevention and Control Period. China Government Network, Central People's Government Portal. http:/www.gov.cn/zhengce/zhengceku/2020-02/05/content_547473 3.htm

[3] Xu X, 2012, Inspiration from the Success of Taobao.com to the Construction of Open University. Adult Education, 32(12): 92-94.

[4] Zhang P, Ding L, Zhang W, 2017, Research on the Concept, Evolution and Effectiveness of flipped Classroom. Journal of Educational Studies, 13(1): 46-55. DOI: 10.14082/j.cnki.1673-1298.2017.0 1.007

[5] Wang Y, Guo C, 2010, Pedagogy, Beijing Normal University Publishing House, Beijing, 182.

[6] Gao S, Cai Y, 1987, Anthology of Education, Hunan Education Publishing House, Changsha, 213.

Publisher's note

Bio-Byword Scientific Publishing remains neutral with regard to jurisdictional claims in published maps and institutional affiliations. 